Table 1. $R_{S^{*}}$ Values of ApRicot Oligosaccharides in Two

\begin{tabular}{|c|c|c|}
\hline \multirow[b]{2}{*}{$\underset{\text { designation } \uparrow}{\text { Oligosaccharide }}$} & \multicolumn{2}{|c|}{$R_{S}$} \\
\hline & $\begin{array}{c}n \text {-Butanol-ethanol- } \\
\text { water } \\
(10: 1: 2 \mathrm{v} / \mathrm{v})\end{array}$ & $\begin{array}{c}\text { Ethyl acetate-pyridine- } \\
\text { water } \\
(8: 2: 1 \mathrm{v} / \mathrm{v})\end{array}$ \\
\hline $\begin{array}{l}K 1+ \\
K^{2} \\
K 3 \\
K 4 \\
K 5 \\
K 6\end{array}$ & $\begin{array}{l}0 \cdot 74 \\
0 \cdot 29 \\
0 \cdot 41 \\
0 \cdot 49 \\
0 \cdot 22 \\
0 \cdot 17\end{array}$ & $\begin{array}{l}0 \cdot 66 \\
0 \cdot 21 \\
0 \cdot 34 \\
0 \cdot 45 \\
0 \cdot 17 \\
0 \cdot 12\end{array}$ \\
\hline
\end{tabular}

* Ratio of the distance travelled by the oligosaccharide to the distance travelled by sucrose, the spots being superimposed on the starting line.

$\dagger$ Numbered in order of displacement from a charcoal column.

$K l$ was not resolved by these solvents.

those synthesized from sucrose by yeast invertase (components $\mathrm{I}-\mathrm{IV}^{4}$ ) and $K 2, K 4, K 5$ and $K 6$ were shown to differ from the sucrose-invertase products. $K 3$ and component II had the same $R_{S}$ values in several solvents; but this is of small significance as component II is a mixture of two sugars ${ }^{5}$ unresolved by paper chromatography.

The occurrence of these fructose-containing oligosaccharides in the apricot suggests the presence of a transfructosidation system. Similar oligosaccharides in the artichoke are apparently formed by enzymic transfer of fructose from inulin to sucrose ${ }^{6}$. In the apricot, sucrose itself is the most likely source of fructosyl radicals.

There are indications that some of these oligosaccharides occur in other fruits. A ketose with an $R_{S}$ value similar to that of the $K \mathrm{I}$ mixture has been detected on paper ehromatograms of pear sugars, and traces of a ketose similar to $K 3$ have been found in extracts of some pears and peaches.

A. S. F. Ash

T. M. Reynolds

Division of Food Preservation and Transport,

Commonwealth Scientific and

Industrial Research Organization, Homebush, N.S.W. June 4.

${ }^{1}$ Fairbairn, N. J., Chem. and Indust., 86 (1953).

${ }^{2}$ Albon, N., Bell, D. J., Btanchard, P. H., Gross, D., and Rundell, J. T., J. Chem. Soc., 24 (1953).

${ }^{3}$ Bacon, J. S. D., and Bell, D. J., J. Chem. Soc., 2528 (1953).

4 Bacon, J. S. D, and Edelman, J., Arch. Biochem., 28, 467 (1950). White, L. M., and Secor, G. E., Arch. Biochem. Biophys., 36, 490 (1952).

${ }^{5}$ Bacon, J. S. D., Biochem. J. (in the press), quoted by Gross, D., Nature, 178,487 (1954).

${ }^{a}$ Edelman, J., and Bacon, J. S. D., Biochem. J., 49, 446 and 529 (1951).

\section{Occurrence of Fatty Acids with Uneven-numbered Carbon Atoms in Natural Fats}

Atrhovgr the occurrence in natural fats of fatty acids eontaining odd-numbered carbon atoms, including $n$-heptadecanoic acid and $n$-pentadecanoic acid, has been claimed by various investigators, subsequent work has invariably revealed that such acids are actually equimolecular mixtures of adjacent members of even-numbered fatty acids. The generally accepted view at the present time is expressed by Hilditch" as follows: "With the solitary exception of isovaleric acid (found only in the depot fats of the dolphin and porpoise) the molecules of all natural straight-chain fatty acids, saturated or unsaturated, contain an even number of carbon atoms". Work in this laboratory, however, suggests that this view is not correct, and that fatty acids containing odd-numbered carbon atoms do, in fact, occut in some natural fats.

Following the isolation of pure $n$-heptadecanoic acid from hydrogenated mutton tallow as previously described $^{2}$, we have now prepared pure $n$-pentadecanoic acid from the same source as well as from hydrogenated shark (Galeorhinus australis) liver oil. It has also been shown ${ }^{3}$ that hydrogenated ox perinepheric fat contains a consecutive series (including odd-numbered carbon acids) of volatile acids from $\mathrm{C}_{2}$ to $\mathrm{C}_{10}$. This indicates the probable presence of normal uneven-numbered saturated or unsaturated acids in natural fats. Further, without recourse to hydrogenation, pure $n$-pentadecanoic acid has been isolated from butter-fat.

This work is still in progress, and the detailed results will be published elsewhere.

F. B. SHORLAND

Fats Research Laboratory,

Department of Scientific and Industrial Research, Wellington, New Zealand. June 8.

${ }^{1}$ Hilditch, T. P., "The Chemical Constitution of Natural Fats", 8 , 2nd edit. (CChapman and Hall, London, 1947)

${ }^{2}$ Hansen, R. P., Shorland, F. B., and Cooke, N. J., Nature, [174, 39 $(1954)]$.

${ }^{3}$ Hansen, R. P., and McInnes, A. G., Nature, [173, 1093 (1954)].

\section{Basic Amino-acids of Silk Fibroin}

IN studies of the constitution of proteins, the basic amino-acids are of particular interest. With silk fibroin, for example, the basic amino-acids are the least frequent of the constituent amino-acid residuee and are therefore indicative of the approximats minimum molecular weight. Coleman and Howitt $\mathrm{t}_{\mathrm{r}}$ deduced from the available analytical data that, assuming the molecule to contain one histidine rosidue, there was present a total of some 390 residues which, accepting the experimental mean residue weight of 78 , implied a molecular weight of approximately 30,000 ; a molecular weight of this order was found by osmotic pressure measurements made on the renatured protein. In the latter connexion, however, Holmes and Smith ${ }^{2}$, by ultracentrifuge and diffusion methods, found a mean molecular weight of $60,000-150,000$ (average 84,000) for water-soluble fibroin. This higher value of the mean molecular weight suggests that, assuming no great error to exist in the value of about 0.4 per cent for the histidine content of fibroin, there are at least two histidine residues in the fibroin molecule. In order to strengthen the available experimental evidence on this point, a careful determination has been made of the basic amino-acids in silk fibroin.

A sample of degummed silk (Bombyx mori) was exhaustively extracted with the azeotropic mixture of benzene and methanol, repeatedly washed with distilled water, and finally air-dried. Two samples of about $1.0 \mathrm{gm}$. were accurately weighed and hydrolysed by refluxing with $25 \mathrm{ml}$. of $5 \mathrm{~N}$ hydrochloric acid for $24 \mathrm{hr}$.; a third sample was examined for moisture content. Hydrochloric acid was removed from each of the hydrolysates by distillation in vacuo and the residue made up to $10 \mathrm{ml}$. with distilled water. Aliquots $(0.20 \mathrm{ml}$.) equivalent to $20 \mathrm{mgm}$. of the original silk fibroin were fractionated on a $0.9 \mathrm{~cm} . \times$ $15 \mathrm{~cm}$. 'Dowex 50' ion-exchange resin column under the conditions described by Moore and Stein ${ }^{3}$ for the separation of basic amino-acids, $2 \mathrm{ml}$. fractions being 